THURSDAY, MAY 25, 1876

\section{LORD CARNARVON'S VIVISECTION BILL}

THE Report of the Royal Commission appointed to consider the question of Vivisection has led to the introduction of a bill into Parliament, the clauses of which restrict the practice of experiments upon living animals to a very great extent. According to the act-

(I) Experiments must be performed with a view only to the advancement, by new discovery, of knowledge which will be useful for saving or prolonging human life, or alleviating human suffering.

(2) In a registered place.

(3) By a person holding a licence from one of her Majesty's principal Secretaries of State.

(4) The animal must, during the whole experiment, be under the complete influence of some anæsthetic, not urari ; and,

(5) Must be killed before it recovers from the influence of the anæsthetic.

(6) The experiment shall not be performed for demonstrational purposes; nor,

(7) For the purpose of attaining manual skill.

It is but natural to suppose that concomitantly with the rapid advances which have, within the last century or so, been made in our knowledge of scientific method, similar progress has occurred in the theory of legislation. And yet our leading politicians, in introducing the above quoted Bill, are bold enough to advance, as a motive for the legal machinery they are endeavouring to enforce, the idea that there is any real stibstantiality in the notion that the lengthening of human life and the alleviation of human suffering can form any direct stimulation to physiological work. In so doing they show how little they are capable of appreciating the spirit of the higher philosopher, whose thoughts and temptations to investigate, however much they may be disguised by secondary motives, are but the involuntary secretion, as it may be termed, of his individual brain. They do not even seem to know that one of the most fundamental of the data of scientific method precludes the possibility of preconceived ideas of any kind forming part of a correctly stated problem.

Next with reference to the licence which must, according to the Bill, be held by all who desire to practice vivisection, we cannot help feeling that any legislation which at all interferes with higher mental work is cumbersome in the extreme; for it appears to us to be quite unjustifiable to trammel in the least, the genuine and honourable exercise of original power, whatever way it tends to show itself. There can be no doubt that the genuine student of biology, in as far as he is a pure student, should be in no way restricted in his researches. The Duke of Somerset's objection also deserves special notice, for "important discoveries are often made by comparatively unknown men, rather than by the most prominent physicians and surgeons, and yet such students were to be prevented from prosecuting their researches."

With regard to educational physiology, quite a different influence is at work. We are among those who think that for the purpose of demonstrating physiological facts to students, vivisectional experiments are, notwithstanding the opinion of Sir James Paget and others to the contrary, not absolutely necessary. One of the physiologists examined before the Commission brought forward the case of the teaching of surgery in our medical schools, in which science the opportunities for obtaining independent practical skill on the living body are nil; and yet we cannot believe that many serious mistakes occur from the want of it.

Such being the case, the supervision of public institutions where physiology is taught is quite in accordance with cur views, as are the restrictions with reference to the employment of anæsthetics, and the destruction of the subjects of experiment before they have recovered consciousness.

As to the exemption of Cats and Dogs, we never heard anything more ludicrous, and we are glad that Lord Winmarleigh-as a member of the Royal Commission his opinion is weighty-objected to the restriction as unnecessary. It may be true, as Lord Carnarvon remarked in the House last Monday night, that the employment of these animals has slightly encouraged theft in their direction; but that this should be, by sober men, accepted as a reason for taxing physiologists to purchase more expensive animals, when a few more stringent sentences in the police courts would remove the evil, seems feeble in the extreme.

Looking at the Jill from a general point of view, its great defect is, in our estimation, its separate existence. The genuine spirit which actuates our nation, if we are not mistaken, is one which looks with disgust at the infliction of pain when unattended with the highest advantages. That this is not the case in some foreign countries we know, and can more fully realise since Dr. Klein has given his evidence before the Royal Commission. No doubt, as Lord Carnarvon remarked, "students are more and more in the habit of frequenting foreign Schools and returning to this country with the traditions and modes of these Schools." Would not a clause or so attached to the previously existing Cruelty to Animals' Act, however, cover all the requirements of the case by enabling an inspector, or a private individual, to prosecute any one performing a vivisection for simple demonstration purposes, or if he publishes results which show that due precaution has not been taken to reduce pain to a minimum in the animal operated on?

\section{WILSON'S "PREHISTORIC MAN"}

Prehistoric Man: Researches into the Origin of Civilisation in the Old and the New World. By Daniel Wilson, LL.D. Third Edition. (Macmillan and Co, I876.)

R. DANIEL WILSON claims the mexit of having introduced the useful term prehistoric, first employed (he says) in 1851 , in his "Prehistoric Annals of Scotland." There its meaning was limited to races preceding the oldest historical nations of Northern Europe. But in the first edition of his "Prehistoric Man," published in I862, it had become a general term for tribes ancient or modern in chronology, as to whom 